\title{
A laparoscopic vascular blocking forceps used for renal carcinoma combined with tumor thrombus
}

\author{
Xinfei Li ${ }^{1}$, Guangpu Ding ${ }^{1}$, Xuesong Li ${ }^{1}$, Liqun Zhou ${ }^{1}$ \\ 1 Department of Urology, Peking University First Hospital. Institute of Urology, Peking University \\ National Urological Cancer Center, Beijing, China
}

\section{ABSTRACT}

Objectives: To discuss the feasibility and efficacy of a laparoscopic vessel blocking forceps in laparoscopic inferior vena cava (IVC) thrombectomy (1-3).

Materials and methods: The patient was secured in a left lateral decubitus position. The surgical field was built with 4-trocar. The laparoscopic vessel blocking forceps was used to block the IVC partially. With the help of the forceps, we completed a retroperitoneal laparoscopic radical nephrectomy and IVC thrombectomy.

Results: The patient was a 73-year-old female. The tumor was located on the right side. Based on the preoperative radiology examination, the tumor thrombus extended from the right renal vein into the IVC, and the cephalic extent of tumor thrombus was $1.6 \mathrm{~cm}$ above the renal vein. The preoperative stage was T3b, and the Mayo grade of the tumor thrombus was grade I. The operation was successfully completed without conversion to open surgery. The operation time was 159 minutes, and the estimated blood loss was about 50ml. No blood transfusion was needed. The postoperative hospital stay was 10 days. No operation related complication was observed. Postoperative pathology showed diffusely poor differentiated carcinoma, and the pathological stage was T3bNo.

Conclusion: The laparoscopic vascular blocking forceps can clamp vessels without damaging the vessels. Vascular blocking forceps is suitable for laparoscopic surgical field. We recommend such a vascular blocking forceps for laparoscopic thrombectomy in patients with renal carcinoma and Mayo grade 0-I tumor thrombus. It may be used to clamp other blood vessels temporarily or control bleeding during laparoscopy in the future.

\section{CONFLICT OF INTEREST}

None declared. 


\section{REFERENCES}

1. Pouliot F, Shuch B, Larochelle JC, Pantuck A, Belldegrun AS. Contemporary management of renal tumors with venous tumor thrombus. J Urol. 2010; 184:833-41; quiz 1235.

2. Shao P, Li J, Qin C, Lv Q, Ju X, Li P, et al. Laparoscopic Radical Nephrectomy and Inferior Vena Cava Thrombectomy in the Treatment of Renal Cell Carcinoma. Eur Urol. 2015; 68:115-22.

3. Steven CC, Brian RL: Malignant Renal Tumors. In: Alan JW(ed.), Campbell-Walsh Urology 11th edition. Philadelphia, Elsevier. 2016; pp. 1314-1364.
Correspondence address:
Xuesong Li, MD
Department of Urology, Peking University First Hospital, Institute of Urology, Peking University National Urological Cancer Center, Beijing, China Xishiku 8, Xicheng District, Beijing, 100034, China Fax:+ 8610 6655-1726

E-mail: pineneedle@sina.com

Submitted for publication: January 30, 2020

Accepted after revision: August 26, 2020

Published as Ahead of Print: December 20, 2020

\section{ARTICLE INFO}

\section{Xinfei Li}

https://orcid.org/0000-0002-4201-2443

Available at: http://www.intbrazjurol.com.br/video-section/20200063_Li_et_al Int Braz J Urol. 2021; 47 (Video \#10): 678-9 